\title{
Design and implementation of IT services as part of the "Smart City" concept
}

\author{
Aleksandr Lepekhin ${ }^{1, *}$, Alexandra Borremans ${ }^{1}$ and Oksana Iliashenko ${ }^{1}$ \\ ${ }^{1}$ Peter the Great St.Petersburg Polytechnic University, Polytechnicheskaya, 29, 195251, \\ St. Petersburg, Russia
}

\begin{abstract}
The concept of "Smart City" is evolving and increasingly becoming important for modern urban society. The state structures, business and institutions increasingly rely on information technology (IT) in its architectural representation. Such transformation of cities is connected with the growing use of software, server infrastructure and client devices in all the most important municipal services. The construction of infrastructure for these municipal services is a complex task, being solved both at the level of the whole city and at the level of individual directions. "Smart healthcare" is an important part of the "Smart City" concept. It is built on scalable storage systems and a communications platform. With this type of IT support, patient records are stored electronically and distributed where they are needed. Construction of "Smart health" ecosystem has to be addressed steadily and on different levels in order to design an infrastructure integrated in the whole-city concept. This research paper discusses the IT services that underlie the concept of "Smart Healthcare", and describes a project for developing software and designing a technology infrastructure for the implementation of these services by major medical centers within the framework of the general concept of "Smart City". The research represents a step-wise analysis of society needs and development of IT-services and application, which are designed to connect the urban infrastructure with inner ecosystem of hospitals. The results of the work can be used as a basis for the design of IT services for e-health and the construction of the "Smart Healthcare" system.
\end{abstract}

\section{Introduction}

The concept of "Smart City" is an emerging paradigm nowadays. Based on the previous studies, the Smart cities are defined by strong foundation on information and communication technologies (ICT) that invest in human and social capital to improve the quality of life of their citizens [1]. A major challenge of "Smart City" concept realization is implementation of e-health system and "Smart healthcare" as a whole on many different levels of urban life of citizens to build a system of healthcare services, influencing the overall wealth level and quality of life.

\footnotetext{
${ }^{*}$ Corresponding author: lepekhinalexander@gmail.com
} 
A major challenge in healthcare is the lack of availability from patient/physician for frequently health monitoring [2]. This includes indoor and outdoor monitoring of vital signs of any patient in order to react rapidly or even prevent different health problems and their outcomes. Wireless and mobile networks offer an adequate and powerful solution to overcome a variety of barriers and provide qualified monitoring and treatments services for citizens.

A vast variety of applications are developed in attempts to evolve the paradigm of ehealth, m-health and Smart healthcare in big cities [3].

One of those examples is the StepUp application. This is a step counter application, which uses sensor-enabled mobile phones to automatically count the number of steps the user walked. The application returns to the user the measured quantity of his/her daily activities and create a healthy competition. The key goal of this solution is to increase awareness and understanding the importance of physical activities and facilitate the integration of regular exercise into their daily life [4].

Another example of an application, which fits the Smart Healthcare concept, could be A Mobile Personal Trainer (MOPET). MOPET is a wearable system that supervises physical activity alternating jogging and fitness exercises in outdoor environments. The main goal of this software is to motivate the user to do sports. It also provides safety and health advices, adapted to the user and his/her context [5].

Another application is iWander. Its main goal is an attempt to partially alleviate stress, financial burden, and offer easier remote monitoring to caregivers by using the user's social network as a monitoring service. The application runs in the background and collects data from the device's sensors such as GPS, time of day, weather condition, stage of dementia, and user feedback. This data is then analyzed to determine the probability the person is wandering. The application then automatically takes actions that help navigate the patient to a safe location, notify caregivers, provide the current location of the patient and call 911 [6].

The solution, which is presented in current research, is WorldWideCare complex system. It gathered contributions from the above described applications and also from number of personal healthcare solutions from different vendors and was developed by Design Thinking approach, targeting citizens and large medical centers. The core concept of WorldWideCare is building the bridge between hospitals infrastructure and urban area by means of ICT in order to increase the quality of life of citizens. This is approach, which has not been discussed yet in current researches and practices, because its main focus is considerably wider than inner healthcare services of medical centers. The solutions aims to provide healthcare services continuously and ubiquitously in "Smart City".

\section{Materials and methods}

The common problems that involve both issues related with the monitoring of personal health and organizational processes in providing healthcare assistance are addressed by means of the current research. These problems were gathered by means of interviewing, shadowing, storyboarding and other Design Thinking techniques. All these techniques were applied in one of the largest Medical Centers of the city [7]. Finally, the diagram, which shows how potentially could the application react on different cases faced by user, was developed and presented in the figure 1 . 


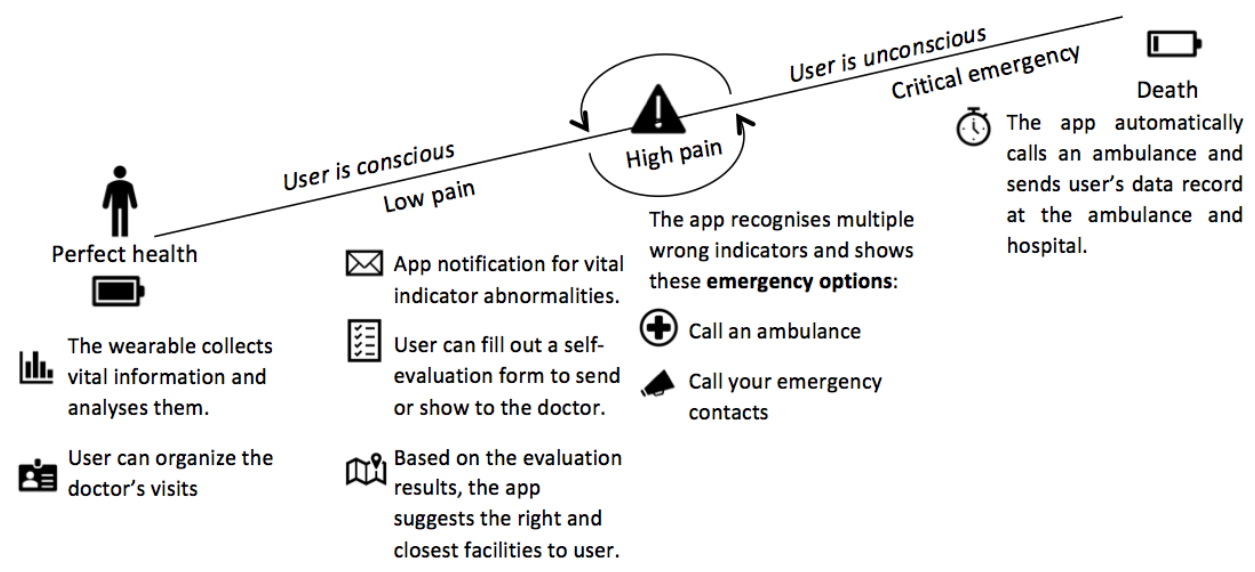

Fig. 1. Application concept.

This Solution is aiming to overcome several problems, which were gathered and analyzed:

- Languages barriers: One of the main difficulties concerns the communication between doctor/nurse and patient. Often happens that the language differences lead to a huge time loss and even to an erroneous diagnosis.

- Mistakes at the reception desk: A very important factor to prevent the loss of valuable time is addressing the patient at the right hospital sector and room.

- Double data storage system: Hospitals are facing the problem of a dual storage system, both in paper and electronic form.

- Faster reaction to critical emergency: When someone suddenly has health issues and is in need of immediate help very often suffers from the slow process of recovery.

The concept of potential solution was adapted from [2] and addresses the M-Health paradigm, which allows to provide a set of services, required to solve the designed problem. Moreover, the peculiarities of telecommunications projects were taken into account [8]. The concept is presented in the figure 2 .

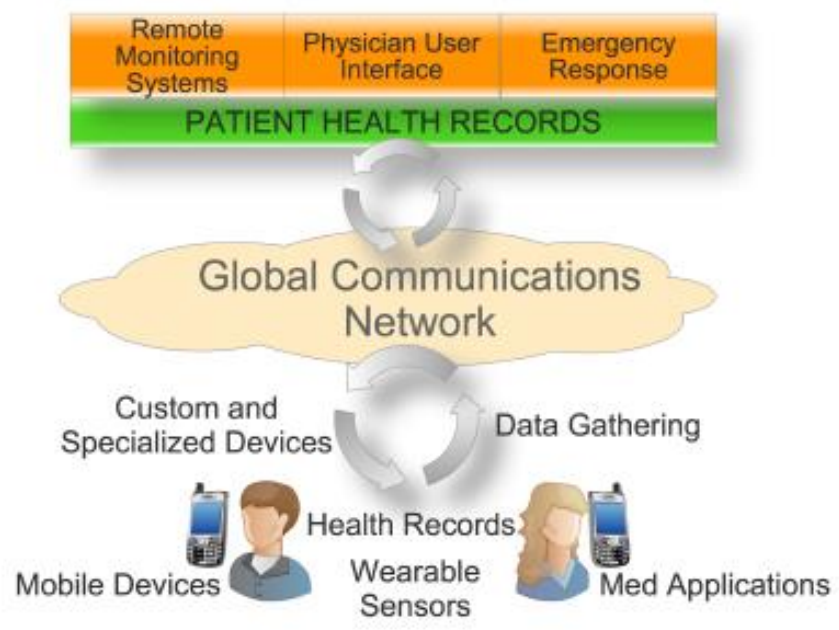

Fig. 2. M-Health services framework. 


\section{Results}

\subsection{User interface and Hardware}

The WorldWideCare application was designed with use of NinjaMock tool based on the design problem, analyzed above. The application in total has the following modes:

- Basic mode - the mode, which ensures Smart Healthcare concept integration in the social life of citizens, providing continues healthcare services and insurance;

- Hospital mode (upgraded version) - the mode, which can be activated inside the hospital or any other healthcare organization to provide higher quality treatment.

The first interface of the application is presented in the figure 3.

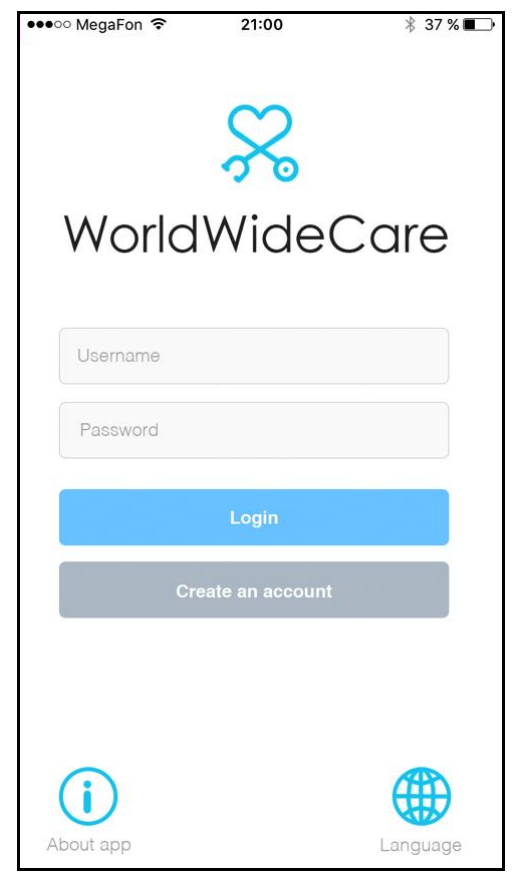

Fig. 3. First screen of application.

The following functionality is embedded in the application in the basic mode:

- Registration / login / logout - providing personal account in WorldWideCare system.

- Change language - the application is integrated with Google Translate API in order to be able to set communication without any barriers [9].

- Check actual health parameters - checking and updating the latest health indicators.

- Edit profile - updating person's information.

- Send a SOS (emergency) signal

o Call ambulance (Share data with ambulance/hospital) - ability to be integrated with ambulance system, send location to be picked up, send data to the hospital, so that the personnel can already be prepared.

o Call emergency contacts (including Set up and customize emergency contacts) ability to reach people from emergency contacts list automatically in critical case.

- Make a self-diagnosis and choose the hospital (doctor) nearby - ability to track and analyze personal healthcare indicators and search for hospitals nearby to make an appointment.

In the Hospital mode the following functions are embedded: 
- Ask for help - provides assistance with asking for help, includes translation functions, helps avoiding problems with misunderstanding between patient and personnel.

- Check timetable of procedures - tracks person's own procedures, which are appointed in scopes of the treatment process.

When the prototype was analyzed critically, it was decided that the Smart bracelet should also become a part of solution. This would help to overcome different problems and improve the overall quality of WorldWideCare system:

- Precise and continuous data collection and analysis;

- An affordable and user-friendly solution for a wide audience;

- Easily customizable size of wearable.

The bracelet design is presented in the figure 4.

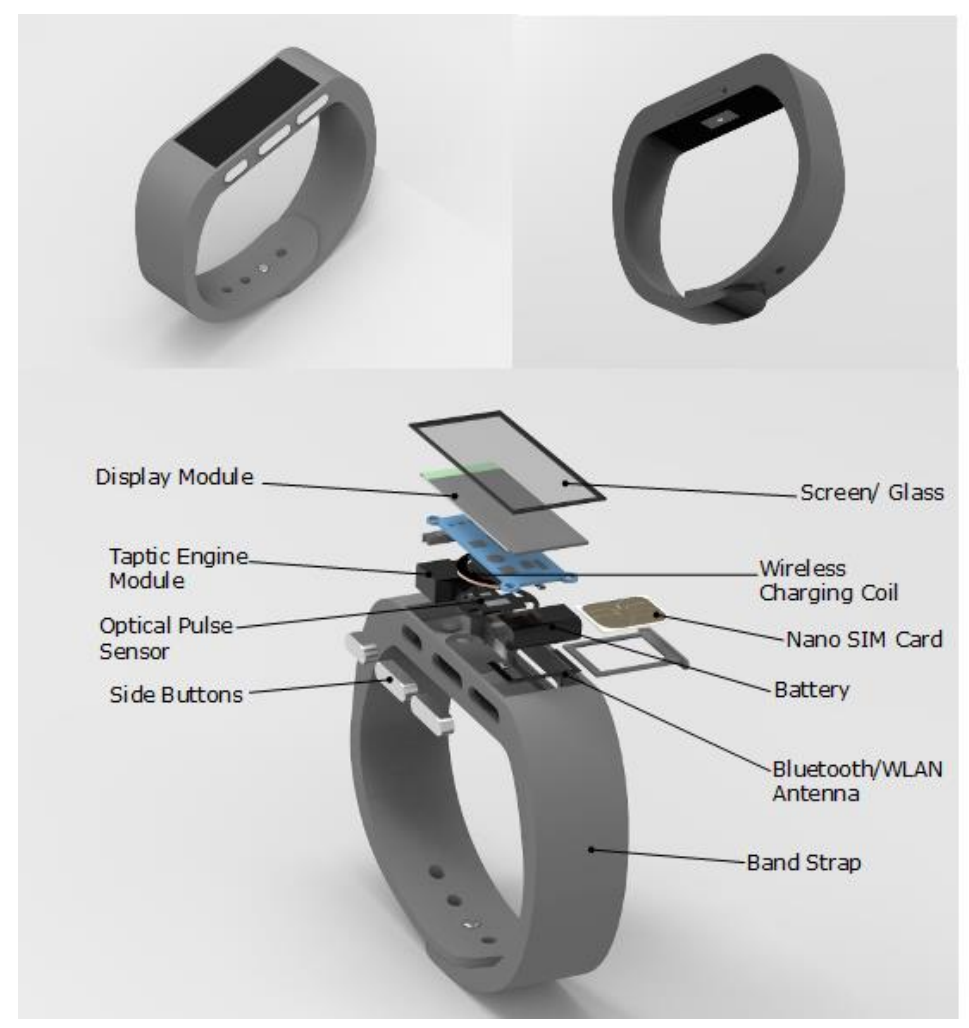

Fig. 4. Wearable prototype.

\subsection{Market analysis}

In order to assess the value of the Solution on the modern IT market, a comparative analysis of competitors was made. Since the proposed Solution is a complex system consisting of an application, a portable device and their integration with the hospital information system, the comparison was made with various applications and wearables. The analysis is presented on the table 1 . 
Table 1. Competitors' analysis.

\begin{tabular}{|l|c|c|c|c|c|c|c|}
\hline \multicolumn{1}{|c|}{ Solution } & $\begin{array}{c}\text { Multilan } \\
\text { guage }\end{array}$ & $\begin{array}{c}\text { Actual } \\
\text { health } \\
\text { parameters }\end{array}$ & $\begin{array}{c}\text { SOS } \\
\text { button }\end{array}$ & $\begin{array}{c}\text { Connection } \\
\text { with } \\
\text { ambulances }\end{array}$ & $\begin{array}{c}\text { Self- } \\
\text { diagnosis }\end{array}$ & $\begin{array}{c}\text { Arrange an } \\
\text { appointment } \\
\text { with doctor }\end{array}$ & $\begin{array}{c}\text { Work } \\
\text { without } \\
\text { Smartphone }\end{array}$ \\
\hline $\begin{array}{l}\text { WorldWideCare } \\
\text { solution }\end{array}$ & $\checkmark$ & $\checkmark$ & $\checkmark$ & $\checkmark$ & $\checkmark$ & $\checkmark$ & $\checkmark$ \\
\hline $\begin{array}{l}\text { SOS button } \\
\text { (iOS } \\
\text { application) }\end{array}$ & $x$ & $x$ & $\checkmark$ & $x$ & $x$ & $x$ & $x$ \\
\hline $\begin{array}{l}\text { iCare (iOS } \\
\text { application) }\end{array}$ & $\checkmark$ & $x$ & $x$ & $x$ & $\checkmark$ & $x$ & $\times$ \\
\hline $\begin{array}{l}\text { iWander } \\
\text { (Android } \\
\text { application) }\end{array}$ & $x$ & $\checkmark$ & $\checkmark$ & $x$ & $x$ & $x$ & $\times$ \\
\hline $\begin{array}{l}\text { Xiaomi Mi } \\
\text { Band 2 } \\
\text { (wearable) }\end{array}$ & $\checkmark$ & $\checkmark$ & $\checkmark$ & $x$ & $x$ & $x$ & $\checkmark$ \\
\hline $\begin{array}{l}\text { Apple Watch } \\
\text { Series 3 } \\
\text { (wearable) }\end{array}$ & $\checkmark$ & $\checkmark$ & $\checkmark$ & $x$ & $x$ & $x$ & $\checkmark$ \\
\hline $\begin{array}{l}\text { Quardio (iOS } \\
\text { application) }\end{array}$ & $\checkmark$ & $\checkmark$ & $x$ & $x$ & $x$ & $x$ & $\times$ \\
\hline
\end{tabular}

Analyzing the obtained data, it can be concluded that WorldWideCare possesses a set of unique functionality that is not represented in other solutions.

\subsection{Implementation opportunities}

The solution was analyzed and mapped within 2 key dimensions in scopes of implementation opportunities - target market and functions. For the target market it was decided to analyze the patients with heart diseases, who were divided into 3 categories: elderly people, patients of hospitals (or those, who are monitored) and people with first symptoms. According to the category of patient, different functionalities, solution's variations and data transmission channels are available. The analysis is presented in the figure 5, where building represents a hospital, car - ambulance, "+" indicates the availability of function, "-" signifies the absence of the function. Elements on the right represent the primary device (wearable or Smartphone).

\begin{tabular}{|c|c|c|c|c|c|c|c|}
\hline $\begin{array}{l}\text { Target } \\
\text { market / } \\
\text { functions }\end{array}$ & $\begin{array}{l}\text { Data } \\
\text { collection } \\
\text { and } \\
\text { analysis }\end{array}$ & $\begin{array}{l}\text { Emergency } \\
\text { alert }\end{array}$ & $\begin{array}{l}\text { Location } \\
\text { and data } \\
\text { sharing }\end{array}$ & $\begin{array}{l}\text { Self- } \\
\text { evaluation }\end{array}$ & $\begin{array}{l}\text { Hospitals } \\
\text { radar, } \\
\text { capacity } \\
\text { and contact }\end{array}$ & $\begin{array}{l}\text { Social } \\
\text { network }\end{array}$ & $\begin{array}{l}\text { Communic } \\
\text { ation } \\
\text { doctor- } \\
\text { patient }\end{array}$ \\
\hline $\begin{array}{l}\text { Elderly } \\
\text { people }\end{array}$ & & & & - & - & - & - \\
\hline Patients & & & & - & - & + & + \\
\hline $\begin{array}{l}\text { First } \\
\text { symptoms }\end{array}$ & + & & & : & & + & - \\
\hline
\end{tabular}

Fig. 5. Implementation opportunities analysis.

Thus the first group of patients - the elderly people - will have the following functions:

- Continuous data collection and analysis; 
- Emergency alert for person in conscious and unconscious state (button press or automatic signal);

- Location and data sharing in case of emergency.

The patients of the medical organizations will have access to the above functions, and the following:

- Social network for the communication among the people with the same disease;

- Channel for direct doctor-patient communication.

For those users, who have only first symptoms of serious diseases and who will actively use application the following functions will be available:

- Self-evaluation in application, where they will be able to describe their problem, by clicking the model;

- Arranging visits to the doctor according to users' location.

\section{Conclusions}

To be able to work properly, the following assumptions has to be taken into account when the application is implemented in the urban area: the application has more use-cases with bracelet but also together with any kind of wearable able to get healthcare data and hospitals and ambulances, as well as citizens (users) are registered in the application.

These assumptions have to be overcome, so that the application implementation would be able to address social understanding and correction of real problems, targeting strong demand and big healthcare-technology market.

Social responsibility is a core objective of Smart Healthcare projects, but another issue is security and privacy. The proposed application is safety-critical solution, the failure would influence person's health. The design of this application (in terms of its backend structure, critical use-cases and other aspects) can be addressed on future researches.

The described system allows creating a network connecting people, medical organizations and ambulances. Such solution increases the efficiency of organizations and improves the quality of provided services. This system is the step towards the digitalization of medicine, what is the basis for improving various spheres of human life and developing the concept of "Smart City".

\section{References}

1. Solanas et al., IEEE Commun. Mag. 52(8), 74-81 (2014)

2. B.M. Silva, I.M. Lopes, J.J. Rodrigues, P. Ray, e-Health Networking Applications and Services (Healthcom), 2011 13th IEEE International Conference on, 375-380 (2011)

A. Bril, O. Kalinina, I. Ilin, MATEC Web of Conferences 106, 8010 (2017)

3. Khalil, S. Glal, Current Trends in Information Technology (CTIT), 1-5 (2009)

4. F. Buttussi, L. Chittaro, Artif. Intell. Med., 42 (2), 153-163 (2008).

5. F. Sposaro, J. Danielson, G. Tyson, Annual international conference of the IEEE Engineering in Medicine and Biology Society (EMBC), 3875-3878 (2010)

6. I.V. Ilin, O.V. Kalinina, A.I. Levina, O.Y. Iliashenko, MATEC Web of Conferences 86,5028 (2016)

7. V.V. Gluhov, I.V. Ilin, International Conference on Next Generation Wired/Wireless Networking, 509-518 (2014)

8. https://cloud.google.com/translate/docs/ 